\title{
Blood oxygenation level-dependent MRI for assessment of renal oxygenation
}

\author{
This article was published in the following Dove Press journal: \\ International Journal of Nephrology and Renovascular Disease \\ 21 November 2014 \\ Number of times this article has been viewed
}

\author{
Joel Neugarten \\ Ladan Golestaneh \\ Renal Division, Montefiore Medical \\ Center, Albert Einstein College of \\ Medicine, Bronx, NY, USA
}

\begin{abstract}
Blood oxygen level-dependent magnetic resonance imaging (BOLD MRI) has recently emerged as an important noninvasive technique to assess intrarenal oxygenation under physiologic and pathophysiologic conditions. Although this tool represents a major addition to our armamentarium of methodologies to investigate the role of hypoxia in the pathogenesis of acute kidney injury and progressive chronic kidney disease, numerous technical limitations confound interpretation of data derived from this approach. BOLD MRI has been utilized to assess intrarenal oxygenation in numerous experimental models of kidney disease and in human subjects with diabetic and nondiabetic chronic kidney disease, acute kidney injury, renal allograft rejection, contrast-associated nephropathy, and obstructive uropathy. However, confidence in conclusions based on data derived from BOLD MRI measurements will require continuing advances and technical refinements in the use of this technique.
\end{abstract}

Keywords: kidney, hypoxia, oxygenation, diabetes mellitus, chronic kidney disease, acute kidney injury, contrast-associated nephropathy, BOLD MRI

\section{Introduction}

Measurement of renal oxygenation has traditionally relied on invasive techniques in animal models. In fact, direct measurement of oxygen partial pressure $\left(\mathrm{pO}_{2}\right)$ by oxygen-sensing electrodes penetrating the renal parenchyma remains the gold standard for assessing renal tissue oxygenation. In humans, renal oxygenation can be inferred from direct measurements of arterial and venous blood oxygen levels. However, in the mid 1990s, blood oxygen level-dependent magnetic resonance imaging (BOLD MRI) emerged as a noninvasive technique to assess intrarenal oxygenation in humans and experimental animals. BOLD MRI utilizes deoxygenated hemoglobin as an endogenous marker to measure tissue oxygenation. The major strength of this technique lies in its ability to perform repeated measurements of renal oxygenation in the same individual without invasive maneuvers that may impact the parameters being measured. However, numerous technical limitations confound interpretation of these data. Studies utilizing this technique to examine renal physiology and disease states are discussed along with limitations in interpretation of the results.

\section{Technical challenges}

BOLD MRI measurements are based on changes in the magnetic properties of hemoglobin that accompany its conversion from oxyhemoglobin to deoxyhemoglobin. Deoxyhemoglobin generates magnetic moment due to its unpaired iron electrons. Increased deoxygenated hemoglobin concentrations lead to alterations in the magnetic 
spin properties of neighboring water molecules, which speeds up magnetic spin dephasing and decreases signal intensity on apparent spin-spin relaxation time-weighted $(\mathrm{T} 2 *)$ magnetic resonance images. The rate of magnetic spin dephasing, $\mathrm{R} 2 *(=1 / \mathrm{T} 2 *)$, is a measure of the tissue content of deoxygenated hemoglobin, which in turn reflects tissue $\mathrm{pO}_{2}$. A decrease in $\mathrm{R} 2 *$ implies decreased deoxygenated hemoglobin concentration and increased tissue $\mathrm{pO}_{2}$. Increasing magnetic field strength from 1.5 to 3 Tesla increases BOLD MRI signal strength and magnifies changes in R2*, resulting in increased sensitivity and reliability, despite an increase in susceptibility artifacts. ${ }^{1}$ The relationship between BOLD MRI signal intensity and renal oxygen tissue levels has been established by direct measurements of tissue $\mathrm{pO}_{2}$ utilizing oxygen-sensing microelectrodes and fiberoptic probes in experimental models of streptozotocin-induced diabetes mellitus and aortic occlusion and before and after furosemide challenge and nitric oxide synthase inhibition, and by correlation with direct measurements of tissue $\mathrm{pO}_{2}$ after changes in inhaled oxygen levels. ${ }^{2-7}$

Numerous technical limitations confound interpretation of BOLD MRI measurements of renal oxygenation. ${ }^{8}$ BOLD MRI signal intensity may be influenced by hydration status, sodium avidity, vascular volume, age, and perhaps the sex of the subjects studied. Vessel geometry and factors that affect the oxygen dissociation curve, such as body temperature, hematocrit, and blood $\mathrm{pH}$, may also influence BOLD MRI signal intensity. ${ }^{8}$ Knowledge of these limitations may help explain discrepant data obtained by different groups of investigators studying the same disease state.

Oxygen partial pressure in the renal cortex is on the shallow portion of the oxyhemoglobin dissociation curve. Therefore, a small change in cortical oxygenation may not be detected by BOLD MRI. In contrast, an identical change in $\mathrm{pO}_{2}$ in the renal medulla may be detected by this technique since the renal medulla lies on a steeper portion of the oxyhemoglobin dissociation curve. ${ }^{8}$

One must also appreciate that tissue oxygen levels are determined by multiple factors. These factors include oxygen delivery via renal blood flow, oxygen consumption determined primarily by sodium transport, efficiency of oxygen utilization, and arteriovenous diffusive shunting of oxygen. BOLD MRI measurements reflect tissue oxygen levels but cannot differentiate between these factors. Moreover, quantitative interpretation of BOLD MRI signal intensity is limited by the fact that these measurements are only indirectly related to tissue oxygen levels and therefore cannot provide quantitative data in the absence of direct calibration. The absolute magnitude of the signal is a less reliable measure than are serial measurements of relative changes in signal intensity in the same subject. Moreover, intersubject variations in hydration status, sodium avidity, hematocrit, and medications that influence oxygen balance may affect the magnitude of the BOLD MRI signal and confound interpretation of data. These factors complicate comparison of signal intensity among different subjects to imply differences in renal tissue $\mathrm{pO}_{2}$. Thus, this technique is best suited to compare changes in individual subjects before and after an intervention. Nevertheless, and despite this caveat, numerous investigators have utilized BOLD MRI to compare renal oxygenation among different groups of subjects.

The use of BOLD MRI signal intensity to reflect tissue oxygenation is predicated on the assumption that tissue oxygen levels are in equilibrium with and are proportional to blood oxygen levels. In disease states, capillary oxygenation may not be in equilibrium with tissue oxygen due to interstitial deposition of extracellular matrix, which may reduce oxygen diffusion from capillaries to the surrounding tissue. Moreover, increases in renal blood flow and oxygen delivery could be dissociated from changes in renal tissue oxygen levels in the absence of changes in oxygen consumption as a result of increased arteriovenous diffusive shunting of oxygen. ${ }^{9}$

The use of the term oxygenation to describe changes in $\mathrm{R} 2 *$ values measured by BOLD MRI is incorrect insofar as these values reflect not only oxygenation but also a myriad of other factors, including hematocrit and tissue water content. However, in the interest of simplicity, we will refer to changes in $\mathrm{R} 2 *$ values as changes in oxygenation except where there is a discrepancy between $\mathrm{R} 2 *$ values measured by BOLD MRI and directly measured $\mathrm{pO}_{2}$.

Studies performed by Pohlmann et $\mathrm{al}^{4}$ have contributed greatly to our understanding of the technical challenges inherent in interpretation of BOLD MRI data. These investigators developed a novel rat model whereby experimental manipulations could be performed remotely with simultaneous monitoring of both intrarenal $\mathrm{pO}_{2}$ by oxygen-sensitive probes and $\mathrm{T} 2 *$ by BOLD MRI in the same kidney. Changes in $\mathrm{T} 2 *$ (an increase in $\mathrm{T} 2 *$ implies increased oxygenation) correlated with changes in intrarenal $\mathrm{pO}_{2}$, but the relationship was confounded by numerous factors, including changes in vascular and tubular volume fraction and factors that influenced oxyhemoglobin dissociation kinetics. The correlation between $\mathrm{T}_{2} *$ and $\mathrm{pO}_{2}$ was significant in all tissue compartments, but varied in strength among the compartments. The correlation was closest in the outer medulla. 
The correlation between $\mathrm{T}^{*} *$ and $\mathrm{pO}_{2}$ also varied among the different experimental interventions (hyperoxia, hypoxia, aortic occlusion). Although T2* also correlated with kidney size, the strongest correlation was observed between $\mathrm{T} 2 *$ and renal blood flow.

The correlation between outer medullary $\mathrm{T} 2 *$ and $\mathrm{pO}_{2}$ was linear for all tissue compartments, whereas cortical T2* and $\mathrm{pO}_{2}$ showed a significant linear correlation only with aortic occlusion. The weak correlation between cortical T2* and $\mathrm{pO}_{2}$ may reflect both arteriovenous diffusive oxygen shunting and hemoglobin saturation kinetics. During aortic occlusion, the fall in $\mathrm{pO}_{2}$ was much greater than the decline in $\mathrm{T} 2 *$. This discordance was associated with reduced kidney size, and may be explained by a reduced blood volume fraction resulting in reduced deoxyhemoglobin volume fraction. During reperfusion, $\mathrm{pO}_{2}$ immediately began to recover, whereas $\mathrm{T} 2 *$ continued to decline before recovering. The authors attributed the slow recovery of $\mathrm{T} 2 *$ to the increased blood volume fraction resulting in increased deoxyhemoglobin volume fraction. However, this conclusion may not be warranted since only one measurement of $\mathrm{T}^{*} *$ was made during the occlusion period and the nadir $\mathrm{T} 2 *$ may not have been documented. These investigators also found that the fall in $\mathrm{T} 2 *$ in response to hypoxia was greater than the fall in $\mathrm{T} 2 *$ during aortic occlusion. They attributed this aberration to a shift in the oxyhemoglobin dissociation curve in response to decreased $\mathrm{pCO}_{2}$ associated with hypoxic respiratory drive and to a larger fall in blood volume fraction during aortic occlusion associated with a greater tubular volume fraction. These differences in the relationship of $2 *$ to $\mathrm{pO}_{2}$ among different tissue compartments and among different experimental manipulations may reflect the contributions of blood and tubular volume fraction and hemoglobin saturation kinetics to BOLD MRI signal strength. These interrelationships clearly confound the use of BOLD MRI measurements to imply intrarenal $\mathrm{pO}_{2}$.

In an attempt to better define the relationship between $\mathrm{R} 2 *$ (an increase in $\mathrm{R} 2 *$ implies reduced oxygenation) and $\mathrm{pO}_{2}$, Zhang et $\mathrm{al}^{5}$ utilized a two-step mathematical model to estimate intrarenal $\mathrm{pO}_{2}$ from $\mathrm{BOLD}$ MRI signals and validated their approach in pigs by direct measurement of tissue $\mathrm{pO}_{2}$ with oxygen-sensing microelectrodes. $\mathrm{pO}_{2}$ measurements and BOLD MRI scans were performed in the same animals 5-7 days apart. These investigators found a linear relationship between their BOLD MRI-derived $\mathrm{pO}_{2}$ calculations and directly measured $\mathrm{pO}_{2}$. Since their validation studies were performed in kidneys from normal animals, it is not clear whether or not their approach may be translated to diseased kidneys. The work of Zhang et $\mathrm{al}^{5}$ also relates to observations made by numerous investigators that chronic kidney disease (CKD), water loading, and the administration of furosemide reduces or eliminates the spatial corticomedullary $\mathrm{pO}_{2}$ gradient as reflected in the loss of corticomedullary differentiation of R2*. Utilizing their mathematical modeling approach, these investigators failed to confirm loss of corticomedullary differentiation after furosemide. These results may be explained by anatomic and physiologic differences between the renal medulla and cortex. Since the renal medulla exhibits reduced vascularity and a lower hematocrit than the cortex, the authors suggest that similar R2* values in the renal cortex and medulla actually reflect a lower $\mathrm{pO}_{2}$ in the medulla.

\section{Investigations of renal physiology}

Most of the high rate of oxygen consumption by the kidney is due to reabsorption of filtered sodium by the medullary thick ascending limb of the loop of Henle. The ratio between glomerular filtration rate (GFR, a determinant of oxygen consumption due to tubular solute delivery and active sodium transport) and renal blood flow (a determinant of oxygen delivery) is the filtration fraction, which is relatively constant in healthy subjects under physiologic conditions. ${ }^{10}$ Under these circumstances, renal tissue oxygenation would tend to be preserved despite a reduction in oxygen delivery due to a proportionate reduction in oxygen consumption. However, the relationship between renal blood flow and intrarenal oxygenation is more complex. Changes in the magnitude of arteriovenous oxygen diffusive shunting in response to changes in renal blood flow also contribute to renal oxygen balance. ${ }^{10}$ The parallel relationship between renal blood flow and renal oxygenation can be dissociated by administration of vasoactive agents and by altered nitric oxide bioavailability as a result of changes in filtration fraction, oxygen consumption, and/or efficiency of oxygen utilization. ${ }^{10}$

\section{Inspiratory oxygen level}

The relationship of tissue $\mathrm{pO}_{2}$, as a function of inhaled fraction of oxygen in the range of $5 \%-70 \%$, to measured R2* in the renal medulla and cortex, was found to be linear in pigs in which renal tissue $\mathrm{pO}_{2}$ was measured directly with oxygen-sensitive electrodes. ${ }^{3}$ Consistent with these observations, inhalation of pure nitrogen or $10 \%$ oxygen reduced oxygenation in all renal compartments in experimental animals., ${ }^{4,112}$

Breathing $100 \%$ oxygen increases arterial plasma $\mathrm{pO}_{2}$, but has a minimal effect on the deoxyhemoglobin/ oxyhemoglobin ratio in healthy subjects since hemoglobin oxygen saturation is nearly complete. However, inhalation of 
$100 \%$ oxygen moderately increases hemoglobin saturation in venous plasma. ${ }^{13}$ In animal models, several investigators have utilized BOLD MRI to demonstrate that breathing pure oxygen increases oxygenation in all renal compartments. ${ }^{4,12}$ Pohlmann et $\mathrm{al}^{4}$ confirmed these findings in pigs with simultaneous BOLD MRI measurements and direct measurements of $\mathrm{pO}_{2}$ performed in the same kidney. Although the data are not entirely consistent, most BOLD MRI studies in humans have demonstrated that breathing $100 \%$ oxygen increases intrarenal oxygenation in the medulla but not in the cortex, suggesting nonsaturation of renal medullary oxygenation under physiologic conditions. ${ }^{13-17}$ Addition of a vasodilator gas exaggerates the medullary response but has a less consistent effect in the cortex. ${ }^{13,15,16}$ In this regard, it is interesting to note that hyperbaric oxygen has been shown to exert a protective effect in an ischemia/reperfusion model in the rat. ${ }^{18}$

\section{Sodium avidity}

A role for dietary sodium intake as a confounder in BOLD MRI studies was demonstrated by Pruijm et al, ${ }^{19}$ who showed that medullary oxygenation was higher after salt loading of sodium-depleted normotensive and hypertensive young men $(n=18)$. The authors demonstrated enhanced proximal tubule sodium reabsorption under low sodium intake conditions, which they postulated led to reduced medullary oxygen consumption by reducing distal sodium delivery and solute transport.

\section{Diuretics}

Furosemide increases medullary oxygenation despite a reduction in medullary blood flow and oxygen delivery. This is due to an overriding decrease in oxygen consumption as a result of inhibition of medullary thick ascending limb sodium transport. ${ }^{20,21}$ In humans studied with BOLD MRI, furosemide increased medullary oxygenation without affecting cortical oxygenation in young healthy volunteers but not in elderly women. ${ }^{20-22}$ Interestingly, chronic furosemide therapy attenuated the increase in medullary oxygenation after furosemide challenge in subjects with renal artery stenosis. $^{23}$

Zhang et $\mathrm{al}^{5}$ evaluated the response to furosemide in pigs. They compared $\mathrm{pO}_{2}$ modeled from BOLD MRI signals with direct measurements of $\mathrm{pO}_{2}$ obtained with oxygen-sensing microelectrodes in a similarly treated group of animals. Medullary $\mathrm{pO}_{2}$ was higher in both analyses. In contrast, directly measured cortical $\mathrm{pO}_{2}$ was relatively unchanged despite an increase in BOLD MRI-modeled cortical $\mathrm{pO}_{2}$. In healthy subjects $(n=9)$ studied by the same investigators, furosemide increased BOLD MRI-modeled $\mathrm{pO}_{2}$ in the medulla but not in the cortex.

In experimental models of diabetes mellitus characterized by global renal hypoxia documented on BOLD MRI, furosemide increased cortical and medullary oxygenation. ${ }^{11,24,25}$ In humans with early type 1 diabetic nephropathy with proteinuria studied by BOLD MRI, furosemide also increased cortical and medullary oxygenation. ${ }^{26}$ Pruijm et al ${ }^{27}$ studied the response to furosemide in healthy controls $(n=45)$, subjects with CKD ( $n=95)$, and treated hypertensive subjects with well-preserved renal function $(n=58)$. The furosemideinduced increase in medullary renal oxygenation seen in healthy controls was blunted in CKD and in hypertensive subjects. The reduced response to furosemide in CKD was attributed to reduced delivery of furosemide to the kidney. The reduced response to furosemide in hypertensive subjects was attributed to enhanced basal proximal sodium reabsorption resulting in decreased distal sodium delivery, solute transport and oxygen consumption, and/or altered mitochondrial metabolism and reduced oxygen consumption.

Administration of acetazolamide to healthy subjects by Brezis et $\mathrm{al}^{28}$ increased cortical but not medullary oxygenation, corresponding to its site of action to inhibit proximal tubule sodium transport. In contrast, Prasad et $\mathrm{al}^{21}$ found no effect of acetazolamide on intrarenal oxygenation in healthy volunteers.

In a porcine model, administration of furosemide reduced $\mathrm{R} 2 *$ in both the renal cortex and medulla, whereas acetazolamide reduced $\mathrm{R} 2 *$ in the cortex but not the medulla. ${ }^{6}$ However, direct measurement of intrarenal $\mathrm{pO}_{2}$ in another group of similarly treated animals demonstrated only an increase in medullary $\mathrm{pO}_{2}$ after administration of furosemide but an increase in both cortical and medullary $\mathrm{pO}_{2}$ after acetazolamide.

Pedersen et $\mathrm{al}^{29}$ showed that furosemide increases water content in all regions of the rat kidney in association with a reduction in $\mathrm{R} 2 *$ that was more prominent in the cortex than in the medulla. Tubular dilation and increased water volume fraction after furosemide might reduce blood and deoxyhemoglobin volume fraction and reduce $\mathrm{R} 2 *$, independent of changes in intrarenal $\mathrm{pO}_{2}$. This scenario might explain the decrease in cortical R2* after furosemide observed in some BOLD MRI studies despite unchanged directly measured cortical $\mathrm{pO}_{2}$. The role of renal water content in influencing BOLD MRI signal strength is an important issue. Spin-spin relaxation rate (R2) is very sensitive to changes in tissue water content and may have effects on $\mathrm{R} 2 *$ that are independent of deoxyhemoglobin content. Prasad et $\mathrm{al}^{21}$ demonstrated that 
changes in R2, and therefore changes in renal water content after water diuresis and after furosemide, contributed little to the BOLD effect. However, Vivier et $\mathrm{al}^{30}$ concluded the opposite. These investigators found that furosemide increased $\mathrm{R} 2 *$ in the renal medulla and to a lesser degree in the renal cortex of healthy subjects. They found that the contribution of $\Delta \mathrm{R} 2$ to $\Delta \mathrm{R} 2 *$ in the medulla were small but significant, whereas the contribution of $\Delta \mathrm{R} 2$ to $\Delta \mathrm{R} 2 *$ in the cortex was large. They suggested that $\Delta \mathrm{R} 2 *$ be corrected for $\Delta \mathrm{R} 2$ to the influence of changes in water content on the BOLD effect. Moreover, these investigators estimated measurement uncertainty due to intraobserver and interobserver variability, and concluded that their data showing increased R2* after furosemide in the renal medulla data were robust while those for the renal cortex were of low confidence.

\section{Water diuresis}

Prasad et $\mathrm{al}^{31}$ and Tumkur et $\mathrm{al}^{32}$ demonstrated that water diuresis increased medullary but not cortical oxygenation in young healthy subjects studied by BOLD MRI, but not so in the elderly. This effect was mediated by increased synthesis of vasodilator prostaglandins which increase renal blood flow and oxygen delivery while inhibiting Na-K-ATPase and reducing oxygen consumption. ${ }^{32}$ Other investigators have demonstrated an increase in both medullary and cortical oxygenation after water diuresis. ${ }^{30}$ In subjects with type 2 diabetes ( $n=9$ ), a duration of diabetes of less than 5 years, and no overt nephropathy, renal medullary oxygenation did not improve with diuresis, as was the case in young healthy volunteers. ${ }^{33}$ Similarly, other investigators have demonstrated that water diuresis failed to improve medullary oxygenation in early type 2 diabetic nephropathy and in healthy subjects at risk for diabetes mellitus, although cortical oxygenation increased slightly. ${ }^{34}$

\section{Angiotensin II}

In animal models, angiotensin II infusion decreases renal oxygenation due to reduced oxygen delivery resulting from vasoconstriction and loss of peritubular capillary beds and increased generation of reactive oxygen species leading to inefficient cellular respiration. ${ }^{35}$ Angiotensin II inhibitors and angiotensin receptor blockers would be expected to increase intrarenal oxygenation by increasing oxygen delivery due to increased renal blood flow, by decreasing oxygen consumption due to decreased filtration fraction and reduced filtered sodium load, and by increasing the efficiency of oxygen utilization due to reduced generation of reactive oxygen species. ${ }^{17}$ These agents ameliorate renal hypoxia in experimental models of diabetes mellitus, in the remnant kidney, and in angiotensin II-mediated models of hypertension, independent of blood pressure control. ${ }^{17}$

Administration of angiotensin II to healthy male subjects examined by BOLD MRI $(n=6)$ led to renal hypoxia. ${ }^{36}$ In healthy subjects $(n=9)$ studied 2 hours after administration of an angiotensin receptor antagonist, cortical but not medullary oxygenation increased. ${ }^{37}$ In another group of healthy subjects $(n=5)$, no change in oxygenation of the renal cortex or medulla was observed after chronic treatment with a direct renin inhibitor or after acute administration of an angiotensin-converting enzyme inhibitor. ${ }^{38}$ Similarly, no change in cortical oxygenation was observed after acute administration of an angiotensin receptor antagonist in healthy subjects. ${ }^{39}$

Pruijm et $\mathrm{a}^{26}$ found no change in renal tissue oxygenation by BOLD MRI after chronic administration of an angiotensin-converting enzyme inhibitor or an angiotensin receptor blockade in type 2 diabetics $(n=12)$ with proteinuria and mild-moderate renal functional impairment. In both diabetic $(n=7)$ and nondiabetic $(n=7)$ subjects with CKD studied by Manotham et al, ${ }^{39}$ cortical hypoxia was reversed 1 hour after administration of an angiotensin receptor antagonist. In contrast, 2 hours after administration of an angiotensin receptor antagonist, oxygenation was unaltered in subjects with CKD due to chronic allograft nephropathy $(n=10) \cdot{ }^{37}$ In diuretic-treated subjects with CKD $(n=5)$, no significant change in oxygenation of the renal cortex or medulla was observed after chronic treatment with a direct renin inhibitor or after acute administration of an angiotensin-converting enzyme inhibitor. ${ }^{38}$ The authors underscored the observation that the T2* cortex to medulla ratio fell in the CKD subjects, but not in healthy volunteers; however, the significance of this observation may be questioned. ${ }^{5}$

Perhaps these inconsistent results reflect different responses to acute versus chronic interruption of the renin/ angiotensin system. However, more general issues may have contributed to inconsistent results obtained by different investigators after the same intervention in the same disease state. For example, differences in the response to renin/ angiotensin system blockade between CKD subjects studied by Manotham et $\mathrm{al}^{39}$ and those studied by Siddiqi et $\mathrm{al}^{38}$ may be due to problems inherent in comparing responses between different groups of subjects who may differ in hematocrit, hydration status, sodium avidity, age, and medication use. Moreover, failure to adequately account for differences in disease-related factors that might influence intrarenal oxygenation, such as glycemic control and the degree of renal 
functional impairment, might also contribute to discrepant results.

\section{Nitric oxide}

In animal models, nitric oxide is thought to increase intrarenal oxygenation by increasing oxygen delivery as a result of vasodilation and increased renal perfusion and by reducing oxygen consumption as a result of inhibition of tubular sodium transport, competition with mitochondrial cytochrome oxidase $\mathrm{C}$, and quenching of oxygen free radicals. Inhibition of nitric oxide synthase reduced medullary oxygenation in rats studied by BOLD MRI, whereas the response in the renal cortex was variable. ${ }^{7,40,41} \mathrm{Li}_{\text {et }} \mathrm{al}^{7}$ measured R2* by BOLD MRI and intrarenal $\mathrm{pO}_{2}$ by oxygen-sensitive microbes in rats treated with an inducible nitric oxide synthase inhibitor and found reduced medullary oxygenation which was attributed, at least in part, to reduced renal blood flow. These investigators demonstrated a hypoxic response to nitric oxide inhibition in both the cortex and medulla of healthy young human volunteers. ${ }^{7}$ A renal hypoxic response to nitric oxide synthase inhibition was also seen in streptozotocin-induced diabetes, but was blunted in diabetic rats subjected to unilateral nephrectomy. ${ }^{40}$ This result was attributed to reduced nitric oxide bioavailability in diabetic animals. In this context, Li et al have also shown a reduced response to nitric oxide inhibition in the kidneys of genetically hypertensive rats. In BOLD MRI studies performed by Menzies et $\mathrm{al}^{41}$ in the rat, acetylcholine increased cortical and medullary oxygenation by a nitric oxide-dependent mechanism. Chronic infusion of angiotensin II abolished the responses to both acetylcholine and nitric oxide synthase inhibition, suggesting that angiotensin II reduced nitric oxide bioavailability. In another study, a role for nitric oxide was demonstrated in mediating the increase in medullary and cortical oxygenation seen after water loading. ${ }^{42}$

\section{Chronic kidney disease}

Fine et $\mathrm{al}^{43}$ were the first to propose the chronic hypoxia hypothesis, which suggests that renal tissue hypoxia is a final common pathway leading to progression of CKD. According to this theory, inciting glomerular injury promotes obliteration of the glomerular microvasculature and downstream peritubular capillaries, leading to renal tissue hypoperfusion and reduced oxygen delivery. Other factors that may promote tissue hypoxia include vasoconstriction due to alterations in the balance of vasoactive substances and the development of anemia. Ongoing tubulointerstitial injury, inflammation, and fibrosis may increase the barrier to oxygen diffusion and further reduce renal tissue oxygen delivery. Generation of reactive oxygen species, increased angiotensin II levels, and reduced levels of nitric oxide may reduce the efficiency of oxygen utilization for sodium transport, increasing oxygen consumption per unit solute transport. Renal hypoxia in turn may promote fibrogenesis, stimulates the release of inflammatory cytokines and the generation of reactive oxygen species, and also increases systemic blood pressure and cellular apoptosis. These processes are postulated to promote progressive kidney injury.

Oxygen balance in the diseased kidney is likely more complex. The mere reduction of renal blood flow and oxygen delivery does not necessarily result in renal hypoxia due to other factors which contribute to renal oxygen balance. For example, progressive CKD is characterized by reduced GFR as well as renal tissue hypoperfusion. A decline in GFR may decrease tubular solute delivery and solute transport which in turn would reduce oxygen utilization. If the reduction in oxygen utilization offsets the reduction in renal oxygen delivery caused by renal tissue hypoperfusion, then the net effect will be no change in renal oxygenation or even renal hyperoxia. Thus, even if we accept the Fine and Norman hypothesis, ${ }^{43}$ we cannot assume that CKD is associated with chronic renal hypoxia, but instead must rely on actual measurements of renal tissue oxygenation. Early CKD may be associated with renal hypoxia but this condition may not extend to more advanced CKD. CKD may be associated with adaptations to hypoxia and anatomic changes that help to maintain oxygen homeostasis. In advanced CKD, reduced GFR and decreased filtered solute load and tubular solute transport may alter the balance between oxygen delivery and oxygen consumption to favor preservation of tissue oxygenation or even hyperoxia despite reduced oxygen delivery. Although studies utilizing early remnant kidney models have demonstrated intrarenal hypoxia by direct measurements of renal tissue $\mathrm{pO}_{2}$ with oxygen-sensing electrodes, this is not the case in more advanced disease where hyperoxia has been demonstrated. Studies performed in a 6-8-week remnant kidney model found increased intrarenal $\mathrm{pO}_{2}$ by direct measurement. ${ }^{44}$ These data are consistent with the hypothesis that, in advanced kidney disease, renal hypoxia may be supplanted by hyperoxia when a reduction in oxygen consumption due to decreased GFR and reduced tubular solute transport outstrips reduced renal oxygen delivery due to renal tissue hypoperfusion.

Numerous investigators have utilized BOLD MRI to assess intrarenal oxygenation in CKD (Figure 1). In subjects with CKD due primarily to chronic glomerulonephritis $(n=11)$, studied by Xin-Long et al, ${ }^{45}$ hypoxia of the cortex and medulla 


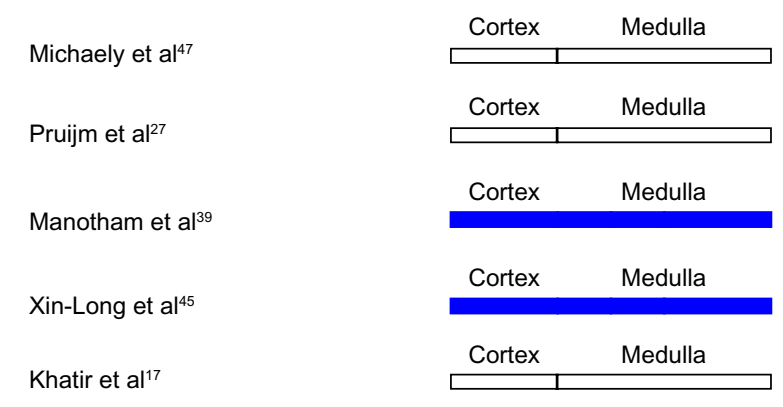

Figure I Intrarenal oxygenation in human subjects with chronic kidney disease studied by blood oxygen level-dependent magnetic resonance imaging.

Note: White indicates no change from control. Blue indicates reduced oxygenation.

was demonstrated by BOLD MRI, despite well preserved GFR in most of the subjects. Manotham et $\mathrm{al}^{39}$ also demonstrated cortical hypoxia in subjects with moderate diabetic $(n=7)$ and nondiabetic $(\mathrm{n}=7) \mathrm{CKD}$. BOLD MRI was utilized by Inoue et $\mathrm{a}^{46}$ to study 76 subjects with nondiabetic CKD primarily due to hypertensive nephrosclerosis and chronic glomerulonephritis. These investigators demonstrated a correlation between estimated GFR and renal oxygenation. In contrast, Djamali et $\mathrm{a}^{37}$ utilized BOLD MRI to demonstrate increased oxygenation in the renal medulla and cortex of subjects with CKD due to chronic allograft nephropathy. To add to this confusion, both Siddiqi et $\mathrm{al}^{38}$ and Khatir et $\mathrm{l}^{17}$ found no difference in renal cortical or medullary oxygenation in subjects with $\mathrm{CKD}$ ( $\mathrm{n}=10$ and $\mathrm{n}=11$, respectively) versus healthy controls.

Michaely et $a l^{47}$ studied a large cohort of subjects with $\mathrm{CKD}$ and found no relationship between BOLD MRI signal intensity and age, sex, estimated GFR, or stage of CKD in a large cohort of 342 subjects with CKD. The authors concluded that progressive kidney disease was not associated with renal hypoxia. These data are inconsistent with the chronic hypoxia hypothesis insofar as reduced intrarenal oxygen levels are predicted, at least in the early stages of CKD. These data also contradict earlier studies of small groups of subjects that demonstrated reduced oxygenation in the elderly and in males as compared with females. However, numerous technical limitations and design flaw confound interpretation of the data reported by Michaely et al. ${ }^{8}$

Pruijm et $\mathrm{al}^{27}$ addressed many of the deficiencies in the study by Michaely et al, ${ }^{47}$ and utilized BOLD MRI to study healthy controls $(n=45)$, subjects with CKD $(n=95)$, and treated hypertensive subjects with well-preserved renal function $(\mathrm{n}=58)$ under standardized conditions of fluid and sodium intake with special attention to medication history and systemic blood pressure. No significant difference in cortical or medullary oxygenation was detected among the groups. Intrarenal oxygenation was independent of the nature of the underlying disease. Neither estimated GFR nor systemic blood pressure correlated with cortical or medullary R2*; however, cortical R2* correlated with male sex, blood glucose levels, and uric acid levels. These data, collected under standardized conditions, suggest that either hypoxia does not play a role in the genesis or progression of CKD in humans or that BOLD MRI is not sensitive enough to detect small differences in renal oxygenation, particularly in light of the heterogeneity of intrarenal tissue oxygenation.

\section{Diabetic nephropathy}

Diabetic nephropathy has been the subject of numerous investigations employing BOLD MRI to assess renal oxygenation in animal models and in humans (Figures 2, 3A and B). 2,11,24-26,40,46-50 With few exceptions, renal hypoxia has been demonstrated by BOLD MRI in experimental models of diabetes mellitus, including streptozotocin-induced diabetes in the rat, Cohen diabetic rats, and $\mathrm{db} / \mathrm{db}$ mice. ${ }^{2,11,24,25,48}$ Of note, Peng et al ${ }^{24}$ also found increased fat content in kidneys from $\mathrm{db} / \mathrm{db}$ mice, which may have contributed to the observed reduction in $\mathrm{T} 2 *$ attributed to hypoxia. Five days after induction of diabetes mellitus in rats with streptozotocin, Ries et a ${ }^{11}$ utilized BOLD MRI to demonstrate hypoxia in all regions of the kidney, in particular in the outer stripe of the outer medulla. Oxygenation did not correlate with glycemia or creatinine levels. Similarly, dos Santos et $\mathrm{al}^{2}$ utilized BOLD MRI to demonstrate decreased cortical and outer medullary oxygenation in rats with streptozotocininduced diabetes mellitus and confirmed these findings by direct measurements of tissue $\mathrm{pO}_{2}$ utilizing oxygen-sensitive microelectrodes. Fourteen days after induction of diabetes mellitus in rats with streptozotocin, Edlund et $\mathrm{a}^{48}$ utilized BOLD MRI to demonstrate reduced oxygenation in the inner stripe of the outer medulla but no change in other regions.

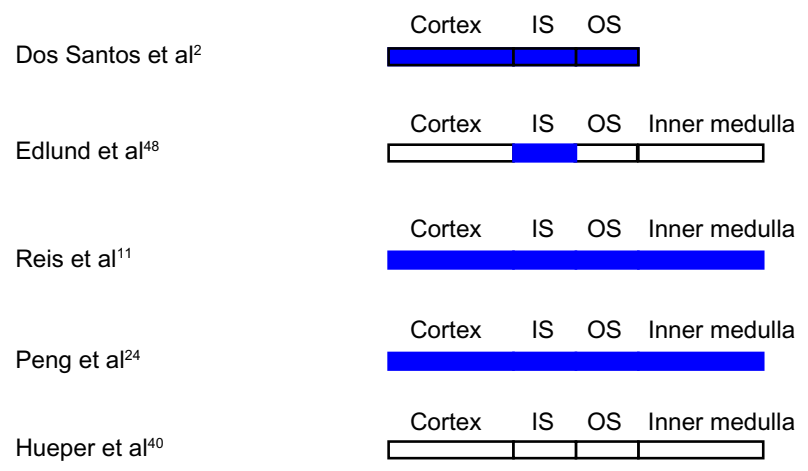

Figure 2 Intrarenal oxygenation in animal models of diabetes mellitus studied by blood oxygen level-dependent magnetic resonance imaging.

Note: White indicates no change from control. Blue indicates reduced oxygenation. Abbreviations: IS, inner stripe of the outer medulla; OS, outer stripe of the outer medulla. 
A

Epstein et $\mathrm{al}^{33}$

Pruijm et $\mathrm{al}^{26}$

Economides et $\mathrm{al}^{34}$

Wang et $\mathrm{al}^{50}$

B

Yin et $\mathrm{al}^{49}$ (preserved GFR)

Yin et al ${ }^{49}$

(more advanced nephropathy)

Figure 3 (A and $\mathbf{B}$ ) Intrarenal oxygenation in human subjects with diabetes mellitus studied by blood oxygen level-dependent magnetic resonance imaging.

Note: White indicates no change from control. Blue indicates reduced oxygenation.

The lighter shade of blue indicates a lesser degree of hypoxia.

Abbreviation: GFR, glomerular filtration rate.

Increased oxygen consumption due to increased tubular transport resulting from hyperfiltration and increased solute delivery may contribute to the development of renal tissue hypoxia. In this regard, furosemide reverses renal hypoxia in experimental diabetes, presumably by decreasing tubular sodium transport and oxygen consumption. ${ }^{11,24,25}$ However, causation is more complex, since renal tissue hypoxia has been dissociated from hyperfiltration in experimental models of diabetes mellitus. ${ }^{51}$ Experimental diabetes mellitus is also associated with mitochondrial dysfunction and reduced efficiency of oxygen utilization due to enhanced generation of reactive oxygen species, increased angiotensin II levels, and reduced nitric oxide availability.

Forty-eight subjects with diabetes were studied with BOLD MRI by Yin et al. ${ }^{49}$ In those with no evidence of clinical nephropathy and in those with preserved GFR, hypoxia of the renal medulla but not the renal cortex was demonstrated. In contrast, in those with more advanced renal involvement, hypoxia of the renal medulla diminished while progressive cortical hypoxia developed. A positive correlation was observed between estimated GFR and hypoxia of the renal medulla. On the other hand, an inverse correlation was demonstrated between estimated GFR and hypoxia of the renal cortex. In contrast, Wang et al ${ }^{50}$ found increased medullary oxygenation in diabetic subjects $(\mathrm{n}=20)$ as compared with controls but no difference in cortical oxygenation. The severity of CKD correlated with the degree of medullary hyperoxia.

Inoue et $\mathrm{a} \mathrm{l}^{46}$ found no correlation between renal oxygenation and estimated GFR in diabetic nephropathy $(n=43)$. Similarly, in subjects with early type 2 diabetic nephropathy $(\mathrm{n}=38)$, studied by Economides et al, ${ }^{34}$ baseline BOLD MRI showed no difference in cortical or medullary oxygenation compared with historical controls. Cortical but not medullary oxygenation correlated with glycemic control. Pruijm et a ${ }^{26}$ also found no difference in renal oxygenation in type 2 diabetics with proteinuria and mild-moderate renal functional impairment $(\mathrm{n}=12)$ compared with historical controls.

It is difficult to reconcile these discordant findings. Possibilities extend well beyond technical and analytic limitations of BOLD MRI. Perhaps, inconsistent conclusions regarding intrarenal oxygenation in diabetic nephropathy or other forms of CKD may also reflect unrecognized or inadequately controlled differences among the groups in disease-related factors or subject-specific variables that influence renal oxygen balance. These issues assume great significance in comparing results from different studies of CKD patients, whether diabetic or nondiabetic, in light of the likely possibility that chronicity as well as the type of CKD may influence renal oxygenation. This speculation underscores the possibility that inadequately controlled differences in disease duration or glycemic control might help explain inconsistent data from different investigators studying the same disease state. In addition, difficulties inherent in comparing BOLD MRI responses between different groups of subjects who may differ in hematocrit, hydration status, sodium avidity, age, and medication use may contribute to discordant findings.

\section{Acute kidney injury Ischemia reperfusion injury}

Utilizing BOLD MRI in swine and rat models of acute renal ischemia, medullary and cortical hypoxia was demonstrated during acute ischemia by BOLD MRI followed by an immediate return to baseline oxygenation after reperfusion. ${ }^{12,51,52}$ Pohlmann et $\mathrm{al}^{4}$ remotely occluded the aorta of rats while simultaneously monitoring intrarenal $\mathrm{pO}_{2}$ by oxygen-sensitive probes and T2* by BOLD MRI in the same kidney. During aortic occlusion, the fall in $\mathrm{pO}_{2}$ was much greater than the decline in $\mathrm{T} 2 *$. During reperfusion, $\mathrm{pO}_{2}$ immediately began to recover whereas $\mathrm{T} 2 *$ continued to decline before recovering. In mice studied with BOLD MRI 1 hour and 24 hours after reperfusion, cortical oxygenation was increased, whereas outer medullary hypoxia persisted. ${ }^{53}$ After longer periods of reperfusion in the rat (3 days), medullary oxygenation was increased despite a reduction in medullary blood flow, with no change in cortical $\mathrm{pO}_{2} \cdot{ }^{54}$ Hyperoxia after ischemia/reperfusion injury may be explained if reduced oxygen consumption due to reduced 
GFR and filtered solute load outweighs reduced oxygen delivery due to hypoperfusion.

\section{Contrast-associated nephropathy}

BOLD MRI has been utilized to study the mechanisms that mediate contrast-associated nephropathy. ${ }^{12,22,42,55-59}$ In rats treated with cyclooxygenase and nitric oxide synthase inhibitors, administration of a first-generation ionic hyperosmolar contrast agent reduced medullary oxygenation. ${ }^{55}$ Administration of a third-generation nonionic, iso-osmolar, high viscosity contrast agent caused an even greater reduction in medullary oxygenation. ${ }^{55}$ Administration of a nonionic hyperosmolar contrast agent to rabbits, studied with BOLD MRI, reduced oxygenation of the inner stripe of the outer medulla. ${ }^{56}$ In human studies utilizing BOLD MRI $(n=10)$, administration of a second-generation nonionic low osmolar contrast agent reduced medullary oxygenation. ${ }^{58}$

In rats and swine studied by BOLD MRI, administration of radiocontrast caused an early and transient increase in medullary $\mathrm{T} 2 *$ followed by a sustained reduction below baseline, with minimal changes observed in the renal cortex. ${ }^{12,22,42,57}$ Arakelyan et $\mathrm{a}^{12}$ attributed the initial rise in $\mathrm{T} 2 *$ to an increase in renal tubular volume due to dye-induced osmotic diuresis resulting in a decreased blood volume fraction. These authors relied on studies by earlier investigators to conclude that medullary blood flow does not change after administration of radiocontrast. However, the immediate effect of contrast administration on medullary blood flow is controversial, and other investigators have demonstrated an initial increase in medullary blood flow which may contribute to the initial rise in $\mathrm{T} 2 *$.

$\mathrm{N}$-acetylcysteine failed to ameliorate intrarenal hypoxia associated with contrast administration in a rat model. ${ }^{59} \mathrm{In}$ contrast, furosemide reversed contrast-induced renal medullary hypoxia in numerous, albeit not all, experimental models of contrast-associated nephropathy studies by BOLD MRI or by direct measurement of intrarenal $\mathrm{pO}_{2} \cdot{ }^{58,59}$ Despite encouraging data in experimental models, furosemide has a deleterious effect on contrast-associated nephropathy in man. The explanation for this disparity remains unclear.

\section{Nephrotoxins}

The effect of various other nephrotoxins on the kidney has been studied by BOLD MRI in several experimental models and in humans. However, the number of studies is small and the models differ in their mechanism of renal injury. For these reasons, no unifying conclusions or significant insights can be drawn as to pathogenic mechanisms based on this body of work. Acute administration of cyclosporine increased medullary and cortical oxygenation in humans studied by BOLD MRI, whereas tacrolimus had no effect. ${ }^{58}$ In contrast, long-term administration of cyclosporine to pigs induced medullary and to a lesser degree cortical hypoxia in the absence of changes in renal blood flow. ${ }^{60}$ Intravenous indomethacin decreased medullary $\mathrm{pO}_{2}$ in the rat, ${ }^{57}$ but oral indomethacin had no effect in humans. ${ }^{58}$ Lastly, administration of gentamicin to rats for up to 7 days increased medullary oxygenation. ${ }^{61}$

\section{Sepsis-associated acute kidney injury}

Tran et $\mathrm{al}^{62}$ studied endotoxemia in mice with BOLD MRI. Renal oxygenation was maintained despite a reduction in renal blood flow. This resulted from reduced oxygen consumption due to reduced renal cytochrome oxidase activity associated with changes in the expression of proteins related to mitochondrial function and oxidative phosphorylation.

\section{Acute tubular necrosis}

Xiao et $\mathrm{al}^{63}$ reported hypoxia of the renal cortex and medulla in subjects with predominantly oliguric acute kidney injury studied by BOLD MRI. BOLD MRI has also been utilized by several investigators to study renal oxygenation in renal allografts with acute tubular necrosis (ATN). The resultant data are conflicting and not readily amenable to interpretation. Sadowski and coworkers reported BOLD MRI measurements in kidney allografts with ATN ( $n=4-6)$ within 4 months post-transplantation. ${ }^{64-66}$ There was no significant difference in cortical oxygenation in the ATN group compared with normal functioning allografts, although one study showed a trend toward cortical hypoxia. Medullary oxygenation was significantly increased in the ATN group in one study, but not in the other two. In contrast, Han et $\mathrm{al}^{67}$ found cortical and medullary hypoxia in allografts with ATN $(n=7)$ compared with normal functioning allografts studied 10 days postoperatively.

\section{Atherosclerotic renovascular disease}

BOLD MRI has been applied to the study of renal oxygenation in kidneys with atherosclerotic renal artery stenosis. The response to furosemide has been utilized to distinguish between viable parenchyma and nonfunctioning renal tissue beyond a stenotic renal artery lesion. By suppressing renal tubular sodium transport and oxygen consumption, furosemide is thought to increase $\mathrm{pO}_{2}$ in viable renal tissue, but has no effect in nonfunctioning renal tissue. 
In a swine model of acute progressive renal artery stenosis, hypoxia of the renal cortex and medulla was demonstrated by BOLD MRI. ${ }^{52}$ In contrast, BOLD MRI studies of chronic renal artery stenosis in the rat, associated with renal atrophy at 4 weeks, demonstrated cortical and medullary oxygenation unchanged from control levels. ${ }^{68}$ These data suggest that chronic renal ischemia may be associated with compensatory changes in renal oxygen metabolism that restore oxygen homeostasis.

Renal cortical hypoxia was demonstrated by Gloviczki et $\mathrm{al}^{69}$ in kidneys with reduced parenchymal volume and impaired GFR which were supplied by arteries with severe stenosis ( $\mathrm{n}=17)$. Furosemide-suppressible oxygen consumption was blunted in these kidneys. In contrast, kidneys with reduced parenchymal volume and impaired GFR, but supplied by arteries with moderate stenosis $(n=13)$, showed preserved cortical and medullary oxygenation despite reduced renal blood flow. These authors suggested that a moderate reduction in renal blood flow may be associated with compensatory mechanisms that preserve renal oxygenation beyond a moderately stenotic renal artery, but that severe renal artery stenosis is associated with a failure of these compensatory mechanisms and the development of renal tissue hypoxia. Underscoring the role of these compensatory mechanisms is an earlier study in which these investigators found no difference in renal oxygenation in stenotic kidneys with reduced parenchymal volume $(\mathrm{n}=14)$ as compared with kidneys from subjects with essential hypertension despite reduced renal blood flow. ${ }^{70}$

Textor et $\mathrm{al}^{71}$ studied subjects with normal-sized kidneys perfused by arteries with high-grade stenosis $(n=29)$ and in some found cortical and medullary hypoxia at baseline. In other kidneys with high-grade stenosis and normal cortical volume, cortical and medullary oxygenation was no different than in normal kidneys. In both groups, cortical and renal medullary oxygenation improved after furosemide. In contrast, totally occluded renal arteries with atrophic kidneys $(n=9)$ showed increased cortical and medullary oxygenation that did not change after administration of furosemide. These investigators concluded that the response to furosemide can be used to distinguish between viable parenchyma (baseline hypoxia with amelioration after furosemide) and nonviable renal tissue (baseline hyperoxia without response to furosemide). Similarly, Gomez et $\mathrm{al}^{72}$ utilized BOLD MRI in a swine model of renal artery stenosis and found that the ability of furosemide to suppress oxygen consumption in stenotic kidneys with reduced GFR was blunted compared with stenotic kidneys with preserved GFR. Consistent with the observations of Textor et al, ${ }^{27}$ Chrysochou et al ${ }^{73}$ found that in humans with atherosclerotic renal artery stenosis, stenotic kidneys with renal hypoxia detected by BOLD MRI were more likely to show a favorable renal functional response to revascularization.

\section{Analytic methods}

Conventional BOLD MRI analysis involves manual selection of discrete regions of interest within the cortex and medullary regions in which signal intensity is measured (Figure 4). Signal intensity within the selected regions of interest are averaged, and a single average $\mathrm{R} * 2$ value is calculated for each compartment. Manual selection of regions of interest introduces observer bias and is subject to errors in delineating the borders of the renal cortex and medulla. In addition, intracompartmental heterogeneity of tissue oxygenation may increase in disease, which may reduce the sensitivity of

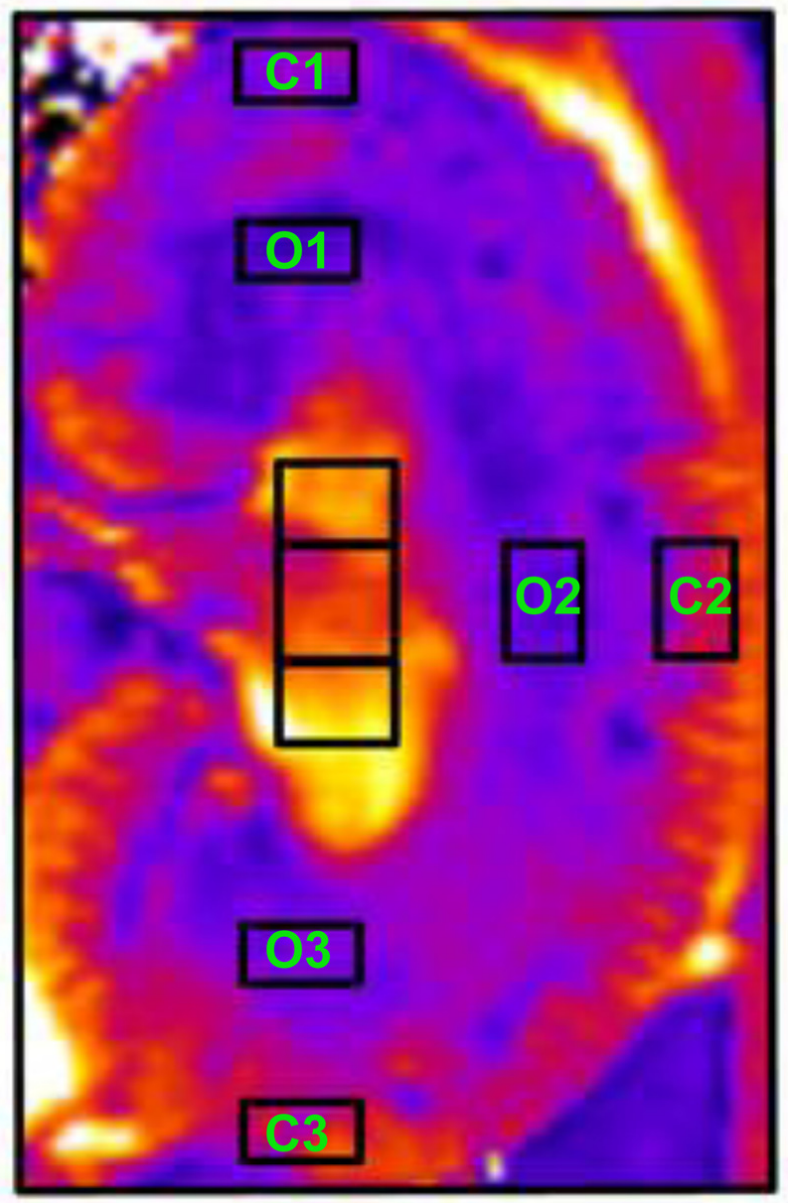

Figure 4 Selection of regions of interest. C I-3 identify cortical regions of interest. O I-3 identify outer medullary regions of interest.

Notes: Adapted from Pohlmann A, Hentschel J, Fechner M, et al. High temporal resolution parametric MRI monitoring of the initial ischemia/reperfusion phase in experimental acute kidney injury. PLoS One. 2013;8(2):e574II ${ }^{83}$ 
BOLD MRI to detect nonuniform alterations in parenchymal tissue oxygenation.

In an attempt to overcome operator bias inherent in manual selection of regions of interest and to better assess intracompartment heterogeneity of oxygenation and thus increase sensitivity, Ebrahimi et al $^{74}$ utilized compartmental analysis of BOLD MRI data in which regions of interest were selected to include the entire axial kidney image section and cortical and medullary R2* distributions were approximated with mathematical functions, and compared this approach with conventional regions of interest selection and with regions of interest selection based on contrast-enhanced computed tomographic images of the same kidney. They found that the compartmental method provided comparable R2* values that were operator-independent and less laborintensive.

Saad et $\mathrm{al}^{75}$ extended the compartmental approach to develop a new analytic method to interpret BOLD MRI data. These investigators introduced the concept of fractional kidney hypoxia, defined as the percent of the entire axial image section with an $\mathrm{R}^{*} 2$ exceeding $30 \mathrm{sec}^{-1}$. To calculate this parameter, the entire axial kidney section is selected, including both the cortex and the medulla. The investigators compared 32 subjects with essential hypertension with 40 subjects who had atherosclerotic renal artery stenosis. Utilizing conventional BOLD MRI data analysis, they found no difference in medullary or cortical oxygenation between stenotic kidneys and their contralateral partner or with kidneys from subjects with essential hypertension. Administration of furosemide increased oxygenation in all groups to a similar degree. However, utilizing fractional kidney hypoxia analysis, stenotic kidneys were found to be hypoxic compared with their contralateral partners and compared with kidneys from subjects with essential hypertension. Furosemideinduced increases in medullary oxygenation were found to be blunted in stenotic kidneys. Hypoxia correlated inversely with renal blood flow and GFR. In evaluating this novel approach, it should be pointed out that fractional tissue hypoxia differed greatly between closely spaced axial sections from the same kidney due to the different fractions of cortex and medulla contained in each section.

The fact that Saad et $\mathrm{al}^{75}$ found that the magnitude and even the direction of their results differed depending on the methodology employed to analyze their data raises significant concerns regarding interpretation of BOLD MRI signals as well as the conclusions derived from these data. It might be argued that until the analytic approach that best reflects the heterogeneity of intrarenal oxygenation is determined, conclusions based on BOLD MRI data remain suspect.

\section{Essential hypertension}

Medullary oxygenation, assessed by BOLD MRI, was lower in hypertensive African-Americans $(n=20)$ than in hypertensive Caucasians $(n=29) .{ }^{76}$ Hypoxia was reversed by administration of furosemide, suggesting overactivity of medullary thick ascending limb sodium transport in hypertensive African-Americans. ${ }^{76}$ However, a normotensive control group was not included for comparison.

Pruijm et al ${ }^{19}$ found increased medullary, but not cortical, oxygenation in untreated young male hypertensive subjects $(n=8)$ as compared with normotensive controls $(n=10)$ at both high and low salt intakes. Mean arterial pressure was correlated with medullary oxygenation, independent of salt intake. These data in humans differ sharply from those obtained in numerous animal models of hypertension in which renal hypoxia has been consistently demonstrated by direct measurement, suggesting that pathogenic mechanisms involved in experimental models of hypertension may not translate to human disease. Moreover, the state of intrarenal oxygenation in older hypertensives remains to be established.

Pruijm et $\mathrm{al}^{27}$ also studied the response to furosemide in healthy controls $(n=42)$ and treated hypertensive subjects with well-preserved renal function $(n=58)$. The furosemideinduced increase in renal oxygenation seen in healthy controls was blunted in hypertensive subjects. The reduced response to furosemide in hypertensive subjects was attributed to reduced oxygen consumption due to enhanced basal proximal sodium reabsorption resulting in decreased distal sodium delivery and solute transport and/or altered mitochondrial metabolism. Interestingly, these investigators found no difference in cortical or medullary oxygenation between treated hypertensives of both sexes with an average age of 57 years versus healthy subjects in contrast with an earlier report from this group showing increased medullary oxygenation in untreated young hypertensive men.

\section{Obstructive uropathy}

BOLD MRI has been utilized to assess renal oxygenation in obstructive uropathy using a swine model of complete unilateral ureteral obstruction. ${ }^{3}$ Medullary oxygenation was increased and cortical oxygenation reduced in both the ipsilateral and contralateral kidneys. After release of obstruction, cortical oxygenation increased slightly but remained below baseline, whereas medullary oxygenation remained unchanged. 
In contrast, unilateral ureteral obstruction increased cortical oxygenation in a susceptible strain of mice. ${ }^{77}$

In human subjects with partial unilateral ureteral obstruction due to renal stones and treated with nonsteroidal anti-inflammatory drugs, medullary and, to a lesser extent, cortical oxygenation were enhanced. ${ }^{78}$ The contralateral nonobstructed kidney showed reduced medullary oxygenation. However, interpretation of these data is confounded by universal exposure of subjects to prostaglandin inhibition.

\section{Kidney transplantation}

Several investigators have explored the utility of BOLD MRI in differentiating acute allograft rejection from ATN in transplanted kidneys (Figure 5A and B). ${ }^{64-67,79,80}$ In three separate publications, Djamali et $\mathrm{al}^{64}$ and Sadowski et $\mathrm{al}^{65,66}$ found that within the first 4 months after renal transplantation, acute rejection ( $n=8-13$ ) was associated with increased renal medullary oxygenation, despite reduced medullary blood flow, as compared with both normally functioning allografts and allografts with ATN. Cortical oxygenation was similar in all groups. In allografts studied by Han et al, ${ }^{67}$ acute rejection ( $\mathrm{n}=21$, studied on average 51 days post-transplantation) was associated with an increase in cortical and a more pronounced increase in medullary oxygenation compared with normally functioning allografts, whereas ATN ( $n=7$, studied on average 10 days post-transplantation) was associated with reduced cortical and medullary oxygenation. In another study performed on average 17 days postoperatively, acute rejection $(n=21)$ was associated with increased medullary and cortical oxygenation compared with normal functioning allografts or healthy volunteers. ${ }^{80}$ Park et $\mathrm{al}^{79}$ found that acute rejection occurring less than 3 months postoperatively $(n=4)$, was associated with increased medullary

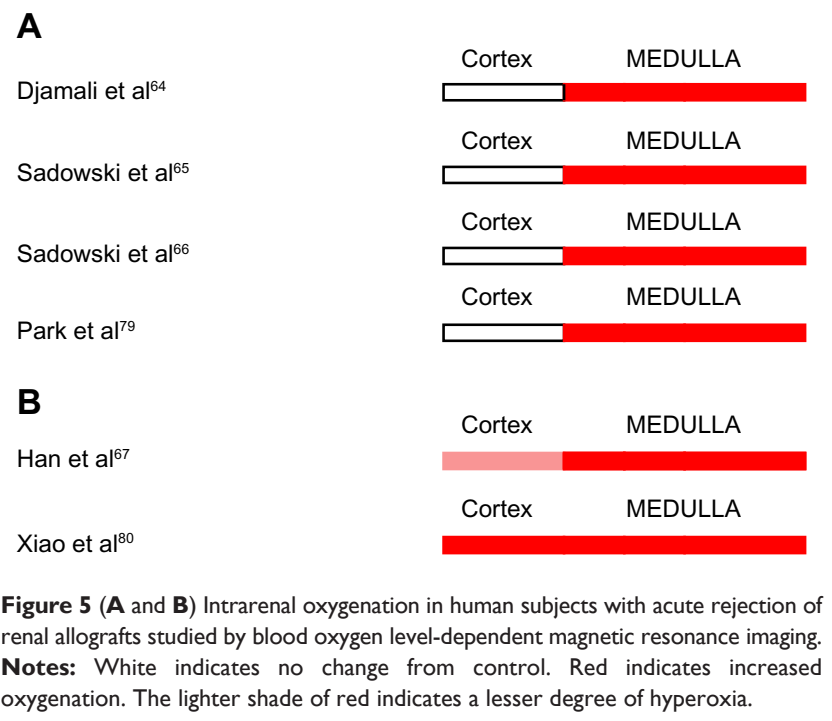

oxygenation and unchanged cortical oxygenation compared with normal functioning allografts.

These data suggest that acute rejection is associated with increased renal medullary oxygenation compared with normally functioning allografts. The level of cortical oxygenation in acutely rejecting renal allografts is less consistent.

Normally functioning allografts $(n=72)$ studied on average 17 days postoperatively were found to demonstrate cortical and medullary oxygenation identical to the kidneys of healthy volunteers. ${ }^{80}$ Similarly, normally functioning allografts $(n=8)$ assessed less than 3 months post-transplantation showed medullary and cortical oxygenation identical to the kidneys of healthy volunteers. ${ }^{79}$ In contrast, in normally functioning allografts ( $n=2)$ studied 4 days postoperatively, medullary and cortical oxygenation was increased compared with predonation levels. ${ }^{81}$ Similarly, medullary oxygenation was increased in renal allografts $(n=9)$ on average 7 months after renal transplantation compared with native kidneys. ${ }^{82}$ When BOLD MRI was repeated at 32 months postoperatively, cortical, but not medullary oxygenation declined as compared with the first scan. ${ }^{82}$ These data on the state of renal oxygenation in normally functioning renal allografts are inconsistent and do not provide clear insights. Results may have been influenced by the time of study and calcineurin inhibitor dosing.

Chronic allograft nephropathy $(n=10)$ was associated with increased renal medullary and cortical oxygenation compared with healthy volunteers. ${ }^{37}$ Hyperoxia correlated with markers of oxidative stress. In this regard, one would predict that oxidative stress would correlate with renal hypoxia, and not hyperoxia as reported, since reactive oxygen species impair the efficiency of oxygen metabolism and increase oxygen consumption per unit solute transport. However, oxidative stress also promotes renal injury and if a reduction in renal blood flow were accompanied by a disproportionate decline in GFR, sodium transport, and overall oxygen consumption, then oxidative stress might actually engender renal hyperoxia. This interpretation mirrors that of other investigators who demonstrated renal hyperoxia in rejecting renal allografts undergoing acute rejection and in severe renal artery stenosis. Perhaps such an analysis highlights the problematic nature surrounding clinical interpretation of BOLD MRI data, ie, one may construe a hypothesis to fit any outcome based on the balance between oxygen delivery and overall oxygen consumption.

\section{Conclusion}

Evolution of BOLD MRI into a more reliable and reproducible indicator of renal oxygenation is required before this technique can realize its full potential to contribute to our 
understanding of the role of renal hypoxia in the pathogenesis of acute kidney injury and progressive CKD. The utility of this technique has clearly been demonstrated in studies investigating the pathogenesis of contrast-associated nephropathy and ischemic nephropathy. However, a role for BOLD MRI as a clinical tool is less clear. This technique shows promise in specific clinical situations, such as identifying acute renal allograft rejection and in predicting response to revascularization of stenotic renal arteries. However, interpretation of the data is confounded by technical limitations in their acquisition and analysis, by a myriad of clinical confounders, and by the likelihood that oxygen metabolism may be influenced both by the type and severity of renal disease. The complexity of these interrelationships is only beginning to be appreciated. The challenge is to develop analytic techniques that address the intracompartmental heterogeneity of renal oxygenation in disease and to construct sophisticated mathematical models that enhance the correlation between BOLD MRI signals and intrarenal $\mathrm{pO}_{2}$. Perhaps use of complementary MRI techniques to simultaneously measure blood volume fraction and intrarenal water and fat content may help separate their contribution to BOLD signal strength from that of tissue $\mathrm{pO}_{2}{ }^{30}$ In this regard, the work of Pohlmann et $\mathrm{al}^{4}$ has helped elucidate the role of confounding factors, such as blood and tubular volume fraction and oxyhemoglobin saturation kinetics, in influencing the relationship between BOLD MRI signal strength and intrarenal oxygenation. The work of Saad et $\mathrm{a}^{75}$ offers great promise in addressing analytic and technical issues that currently limit the ability of BOLD MRI to address intracompartmental heterogeneity in oxygenation, while the work of Zhang et $\mathrm{al}^{5}$ offers great promise in enhancing the ability of BOLD MRI signal strength to reflect intrarenal $\mathrm{pO}_{2}$.

\section{Disclosure}

The authors report no conflicts of interest in this work.

\section{References}

1. Gloviczki ML, Glockner J, Gomez SI, et al. Comparison of 1.5 and $3 \mathrm{~T}$ BOLD MR to study oxygenation of kidney cortex and medulla in human renovascular disease. Invest Radiol. 2009;44(9):566-571.

2. dos Santos EA, Li LP, Ji L, Prasad PV. Early changes with diabetes in renal medullary hemodynamics as evaluated by fiberoptic probes and BOLD magnetic resonance imaging. Invest Radiol. 2007;42(3): $157-162$.

3. Pedersen M, Dissing TH, Mørkenborg J, et al. Validation of quantitative BOLD MRI measurements in kidney: application to unilateral ureteral obstruction. Kidney Int. 2005;67(6):2305-2312.

4. Pohlmann A, Arakelyan K, Hentschel J, et al. Detailing the relation between renal $\mathrm{T}_{2} *$ and renal tissue pO 2 using an integrated approach of parametric magnetic resonance imaging and invasive physiological measurements. Invest Radiol. 2014;49(8):547-560.
5. Zhang JL, Morrell G, Rusinek H, et al. Measurement of renal tissue oxygenation with blood oxygen level-dependent MRI and oxygen transit modeling. Am J Physiol Renal Physiol. 2014;306(6):F579-F587.

6. Warner L, Glockner JF, Woollard J, Textor SC, Romero JC, Lerman LO. Determinations of renal cortical and medullary oxygenation using blood oxygen level-dependent magnetic resonance imaging and selective diuretics. Invest Radiol. 2011;46(1):41-47.

7. Li LP, Ji L, Santos E, Dunkle E, Pierchala L, Prasad P. Effect of nitric oxide synthase inhibition on intrarenal oxygenation as evaluated by blood oxygenation level-dependent magnetic resonance imaging. Invest Radiol. 2009;44(2):67-73.

8. Neugarten J. Renal BOLD-MRI and assessment for renal hypoxia. Kidney Int. 2012;81(7):613-614.

9. Leong CL, Anderson WP, O’Connor PM, Evans RG. Evidence that renal arterial-venous oxygen shunting contributes to dynamic regulation of renal oxygenation. Am J Physiol Renal Physiol. 2007;292(6): F1726-F1733.

10. Evans RG, Ince C, Joles JA, et al. Haemodynamic influences on kidney oxygenation: clinical implications of integrative physiology. Clin Exp Pharmacol Physiol. 2013;40(2):106-122.

11. Ries M, Basseau F, Tyndal B, et al. Renal diffusion and BOLD MRI in experimental diabetic nephropathy. Blood oxygen level-dependent. J Magn Reson Imaging. 2003;17(1):104-113.

12. Arakelyan K, Cantow K, Hentschel J, et al. Early effects of an X-ray contrast medium on renal T(2) */T(2) MRI as compared to short-term hyperoxia, hypoxia and aortic occlusion in rats. Acta Physiol (Oxf). 2013;208(2):202-213.

13. O'Connor JP, Naish JH, Jackson A, et al. Comparison of normal tissue R1 and R*2 modulation by oxygen and carbogen. Magn Reson Med. 2009;61(1):75-83.

14. Jones RA, Ries M, Moonen CT, Grenier N. Imaging the changes in renal T1 induced by the inhalation of pure oxygen: a feasibility study. Magn Reson Med. 2002;47(4):728-735.

15. Donati OF, Nanz D, Serra AL, Boss A. Quantitative BOLD response of the renal medulla to hyperoxic challenge at $1.5 \mathrm{~T}$ and 3.0T. NMR Biomed. 2012;25(10):1133-1138.

16. Boss A, Martirosian P, Jehs MC, et al. Influence of oxygen and carbogen breathing on renal oxygenation measured by $\mathrm{T} 2 *$-weighted imaging at 3.0 T. NMR Biomed. 2009;22(6):638-645.

17. Khatir DS, Pedersen M, Jespersen B, Buus NH. Reproducibility of MRI renal artery blood flow and BOLD measurements in patients with chronic kidney disease and healthy controls. J Magn Reson Imaging. November 5, 2013. [Epub ahead of print.]

18. Ramalho RJ, de Oliveira PS, Cavaglieri RC, et al. Hyperbaric oxygen therapy induces kidney protection in an ischemia/reperfusion model in rats. Transplant Proc. 2012;44(8):2333-2336.

19. Pruijm M, Hofmann L, Maillard M, et al. Effect of sodium loading/ depletion on renal oxygenation in young normotensive and hypertensive men. Hypertension. 2010;55(5):1116-1122.

20. Epstein FH, Prasad P. Effects of furosemide on medullary oxygenation in younger and older subjects. Kidney Int. 2000;57(5): 2080-2083.

21. Prasad PV, Edelman RR, Epstein FH. Noninvasive evaluation of intrarenal oxygenation with BOLD MRI. Circulation. 1996;94(12): 3271-3275.

22. Haneder S, Augustin J, Jost G, et al. Impact of iso- and low-osmolar iodinated contrast agents on BOLD and diffusion MRI in swine kidneys. Invest Radiol. 2012;47(5):299-305.

23. Hall ME, Rocco MV, Morgan TM, et al. Chronic diuretic therapy attenuates renal BOLD magnetic resonance response to an acute furosemide stimulus. J Cardiovasc Magn Reson. 2014;16(1):17.

24. Peng XG, Bai YY, Fang F, et al. Renal lipids and oxygenation in diabetic mice: noninvasive quantification with MR imaging. Radiology. 2013;269(3):748-757.

25. Prasad P, Li LP, Halter S, Cabray J, Ye M, Batlle D. Evaluation of renal hypoxia in diabetic mice by BOLD MRI. Invest Radiol. 2010;45(12): 819-822. 
26. Pruijm M, Hofmann L, Zanchi A, et al. Blockade of the reninangiotensin system and renal tissue oxygenation as measured with BOLD-MRI in patients with type 2 diabetes. Diabetes Res Clin Pract. 2013;99(2):136-144.

27. Pruijm M, Hofmann L, Piskunowicz M, et al. Determinants of renal tissue oxygenation as measured with BOLD-MRI in chronic kidney disease and hypertension in humans. PLoS One. 2014;9(4):e95895.

28. Brezis M, Agmon Y, Epstein FH. Determinants of intrarenal oxygenation. I. Effects of diuretics. Am J Physiol. 1994;267(6 Pt 2):F1059-F1062.

29. Pedersen M, Vajda Z, Stødkilde-Jørgensen H, Nielsen S, Frøkiaer J. Furosemide increases water content in renal tissue. Am J Physiol Renal Physiol. 2007;292(5):F1645-F1651.

30. Vivier PH, Storey P, Chandarana H, et al. Renal blood oxygenation level-dependent imaging: contribution of R2 to R2* values. Invest Radiol. 2013;48(7):501-508.

31. Prasad PV, Epstein FH. Changes in renal medullary pO2 during water diuresis as evaluated by blood oxygenation level-dependent magnetic resonance imaging: effects of aging and cyclooxygenase inhibition. Kidney Int. 1999;55(1):294-298.

32. Tumkur SM, Vu AT, Li LP, Pierchala L, Prasad PV. Evaluation of intra-renal oxygenation during water diuresis: a time-resolved study using BOLD MRI. Kidney Int. 2006;70(1):139-143.

33. Epstein FH, Veves A, Prasad PV. Effect of diabetes on renal medullary oxygenation during water diuresis. Diabetes Care. 2002;25(3): 575-578.

34. Economides PA, Caselli A, Zuo CS, et al. Kidney oxygenation during water diuresis and endothelial function in patients with type 2 diabetes and subjects at risk to develop diabetes. Metabolism. 2004;53(2): 222-227.

35. Nangaku M, Inagi R, Miyata T, Fujita T. Angiotensin-induced hypoxia in the kidney: functional and structural changes of the renal circulation. Adv Exp Med Biol. 2007;618:85-99.

36. Schachinger H, Klarhöfer M, Linder L, Drewe J, Scheffler K. Angiotensin II decreases the renal MRI blood oxygenation leveldependent signal. Hypertension. 2006;47(6):1062-1066.

37. Djamali A, Sadowski EA, Muehrer RJ, et al. BOLD-MRI assessment of intrarenal oxygenation and oxidative stress in patients with chronic kidney allograft dysfunction. Am J Physiol Renal Physiol. 2007;292(2):F513-F522.

38. Siddiqi L, Hoogduin H, Visser F, Leiner T, Mali WP, Blankestijn PJ. Inhibition of the renin-angiotensin system affects kidney tissue oxygenation evaluated by magnetic resonance imaging in patients with chronic kidney disease. J Clin Hypertens (Greenwich). 2014;16(3):214-218.

39. Manotham K, Ongvilawan B, Urusopone P, et al. Angiotensin II receptor blocker partially ameliorated intrarenal hypoxia in chronic kidney disease patients: a pre-/post-study. Intern Med J. 2012;42(4):e33-e37.

40. Hueper K, Hartung D, Gutberlet M, et al. Assessment of impaired vascular reactivity in a rat model of diabetic nephropathy: effect of nitric oxide synthesis inhibition on intrarenal diffusion and oxygenation measured by magnetic resonance imaging. Am J Physiol Renal Physiol. 2013;305(10):F1428-F1435.

41. Menzies RI, Zammit-Mangion A, Hollis LM, et al. An anatomically unbiased approach for analysis of renal BOLD magnetic resonance images. Am J Physiol Renal Physiol. 2013;305(6):F845-F852.

42. Haque M, Franklin T, Prasad P. Renal oxygenation changes during water loading as evaluated by BOLD MRI: effect of NOS inhibition. J Magn Reson Imaging. 2011;33(4):898-901.

43. Fine LG, Orphanides C, Norman JT. Progressive renal disease: the chronic hypoxia hypothesis. Kidney Int Suppl. 1998;65:S74-S78.

44. Priyadarshi A, Periyasamy S, Burke TJ, Britton SL, Malhotra D, Shapiro JI. Effects of reduction of renal mass on renal oxygen tension and erythropoietin production in the rat. Kidney Int. 2002;61(2): 542-546.

45. Xin-Long P, Jing-Xia X, Jian-Yu L, Song W, Xin-Kui T. A preliminary study of blood-oxygen-level-dependent MRI in patients with chronic kidney disease. Magn Reson Imaging. 2012;30(3):330-335.
46. Inoue $\mathrm{T}$, Kozawa $\mathrm{E}$, Okada $\mathrm{H}$, et al. Noninvasive evaluation of kidney hypoxia and fibrosis using magnetic resonance imaging. J Am Soc Nephrol. 2011;22(8):1429-1434.

47. Michaely HJ, Metzger L, Haneder S, Hansmann J, Schoenberg SO, Attenberger UI. Renal BOLD-MRI does not reflect renal function in chronic kidney disease. Kidney Int. 2012;81(7):684-689.

48. Edlund J, Hansell P, Fasching A, et al. Reduced oxygenation in diabetic rat kidneys measured by $\mathrm{T} 2 *$ weighted magnetic resonance micro-imaging. Adv Exp Med Biol. 2009;645:199-204.

49. Yin WJ, Liu F, Li XM, et al. Noninvasive evaluation of renal oxygenation in diabetic nephropathy by BOLD-MRI. Eur J Radiol. 2012;81(7): 1426-1431.

50. Wang ZJ, Kumar R, Banerjee S, Hsu CY. Blood oxygen level-dependent (BOLD) MRI of diabetic nephropathy: preliminary experience. J Magn Reson Imaging. 2011;33(3):655-660.

51. Alford SK, Sadowski EA, Unal O, et al. Detection of acute renal ischemia in swine using blood oxygen level-dependent magnetic resonance imaging. J Magn Reson Imaging. 2005;22(3):347-353.

52. Juillard L, Lerman LO, Kruger DG, et al. Blood oxygen leveldependent measurement of acute intra-renal ischemia. Kidney Int. 2004;65(3):944-950.

53. Oostendorp M, de Vries EE, Slenter JM, et al. MRI of renal oxygenation and function after normothermic ischemia-reperfusion injury. NMR Biomed. 2011;24(2):194-200.

54. Pedersen M, Laustsen C, Perot V, Basseau F, Moonen C, Grenier N. Renal hemodynamics and oxygenation in transient renal artery occluded rats evaluated with iron-oxide particles and oxygenation-sensitive imaging. Z Med Phys. 2010;20(2):134-142.

55. Li LP, Franklin T, Du H, et al. Intrarenal oxygenation by blood oxygenation level-dependent MRI in contrast nephropathy model: effect of the viscosity and dose. J Magn Reson Imaging. 2012;36(5):1162-1167.

56. Zhang Y, Wang J, Yang X, et al. The serial effect of iodinated contrast media on renal hemodynamics and oxygenation as evaluated by ASL and BOLD MRI. Contrast Media Mol Imaging. 2012;7(4): 418-425.

57. Prasad PV, Priatna A, Spokes K, Epstein FH. Changes in intrarenal oxygenation as evaluated by BOLD MRI in a rat kidney model for radiocontrast nephropathy. J Magn Reson Imaging. 2001;13(5):744-747.

58. Hofmann L, Simon-Zoula S, Nowak A, et al. BOLD-MRI for the assessment of renal oxygenation in humans: acute effect of nephrotoxic xenobiotics. Kidney Int. 2006;70(1):144-150.

59. Li LP, Thacker J, Lu J, et al. Efficacy of preventive interventions for iodinated contrast-induced acute kidney injury evaluated by intrarenal oxygenation as an early marker. Invest Radiol. 2014;49(10):647-652.

60. Kristensen DH, Pederson M, Gron MC, et al J. Intrarenal blood oxygenation and renal function measured by magnetic resonance imaging during long-term cyclosporine treatment. Transplant Proc. 2005;37(8):3302-3304.

61. Cao J, Yang XD, Wang XY, Qu L, Liu G, Li XM. [Differential changes of intrarenal oxygenation in rat models of acute tubular necrosis caused by aristolochic acid and gentamicin]. Zhonghua Yi Xue Za Zhi. 2010;90(17):1208-1212. Chinese.

62. Tran M, Tam D, Bardia A, et al. PGC- $1 \alpha$ promotes recovery after acute kidney injury during systemic inflammation in mice. $J$ Clin Invest. 2011;121(10):4003-4014.

63. Xiao WB, Wang QD, Xu JJ, Han F, Zhang MM. [Evaluation of kidney oxygen bioavailability in acute renal failure by blood oxygen level dependent magnetic resonance imaging]. Zhejiang Da Xue Xue Bao Yi Xue Ban. 2010;39(2):157-162. Chinese.

64. Djamali A, Sadowski EA, Samaniego-Picota M, et al. Noninvasive assessment of early kidney allograft dysfunction by blood oxygen level-dependent magnetic resonance imaging. Transplantation. 2006;82(5):621-618

65. Sadowski EA, Djamali A, Wentland AL, et al. Blood oxygen leveldependent and perfusion magnetic resonance imaging: detecting differences in oxygen bioavailability and blood flow in transplanted kidneys. Magn Reson Imaging. 2010;28(1):56-64. 
66. Sadowski EA, Fain SB, Alford SK, et al. Assessment of acute renal transplant rejection with blood oxygen level-dependent MR imaging: initial experience. Radiology. 2005;236(3):911-919.

67. Han F, Xiao W, Xu Y, et al. The significance of BOLD MRI in differentiation between renal transplant rejection and acute tubular necrosis. Nephrol Dial Transplant. 2008;23(8):2666-2672.

68. Rognant N, Guebre-Egziabher F, Bacchetta J, et al. Evolution of renal oxygen content measured by BOLD MRI downstream a chronic renal artery stenosis. Nephrol Dial Transplant. 2011;26(4):1205-1210.

69. Gloviczki ML, Glockner JF, Crane JA, et al. Blood oxygen leveldependent magnetic resonance imaging identifies cortical hypoxia in severe renovascular disease. Hypertension. 2011;58(6):1066-1072.

70. Gloviczki ML, Glockner JF, Lerman LO, et al. Preserved oxygenation despite reduced blood flow in poststenotic kidneys in human atherosclerotic renal artery stenosis. Hypertension. 2010;55(4):961-966.

71. Textor SC, Glockner JF, Lerman LO, et al. The use of magnetic resonance to evaluate tissue oxygenation in renal artery stenosis. J Am Soc Nephrol. 2008;19(4):780-788.

72. Gomez SI, Warner L, Haas JA, et al. Increased hypoxia and reduced renal tubular response to furosemide detected by BOLD magnetic resonance imaging in swine renovascular hypertension. Am J Physiol Renal Physiol. 2009;297(4):F981-F986.

73. Chrysochou C, Mendichovszky IA, Buckley DL, Cheung CM, Jackson A, Kalra PA. BOLD imaging: a potential predictive biomarker of renal functional outcome following revascularization in atheromatous renovascular disease. Nephrol Dial Transplant. 2012;27(3):1013-1019.

74. Ebrahimi B, Gloviczki M, Woollard JR, Crane JA, Textor SC, Lerman LO. Compartmental analysis of renal BOLD MRI data: introduction and validation. Invest Radiol. 2012;47(3):175-182.

75. Saad A, Crane J, Glockner JF, et al. Human renovascular disease: estimating fractional tissue hypoxia to analyze blood oxygen leveldependent MR. Radiology. 2013;268(3):770-778.
76. Textor SC, Gloviczki ML, Flessner MF, et al. Association of filtered sodium load with medullary volumes and medullary hypoxia in hypertensive African Americans as compared with whites. Am J Kidney Dis. 2012;59(2):229-237.

77. Haque ME, Franklin T, Bokhary U, et al. Longitudinal changes in MRI markers in a reversible unilateral ureteral obstruction mouse model: preliminary experience. J Magn Reson Imaging. 2014;39(4): $835-841$.

78. Thoeny HC, Kessler TM, Simon-Zoula S, et al. Renal oxygenation changes during acute unilateral ureteral obstruction: assessment with blood oxygen level-dependent MR imaging - initial experience. Radiology. 2008;247(3):754-761.

79. Park SY, Kim CK, Park BK, Huh W, Kim SJ, Kim B. Evaluation of transplanted kidneys using blood oxygenation level-dependent MRI at $3 \mathrm{~T}$ a preliminary study. AJR Am J Roentgenol. 2012;198(5):1108-1114.

80. Xiao W, Xu J, Wang Q, Xu Y, Zhang M. Functional evaluation of transplanted kidneys in normal function and acute rejection using BOLD MR imaging. Eur J Radiol. 2012;81(5):838-845.

81. Malvezzi P, Bricault I, Terrier N, Bayle F. Evaluation of intrarenal oxygenation by blood oxygen level-dependent magnetic resonance imaging in living kidney donors and their recipients: preliminary results. Transplant Proc. 2009;41(2):641-644.

82. Vermathen P, Binser T, Boesch C, Eisenberger U, Thoeny HC. Three-year follow-up of human transplanted kidneys by diffusion-weighted MRI and blood oxygenation level-dependent imaging. J Magn Reson Imaging. 2012;35(5):1133-1138.

83. Pohlmann A, Hentschel J, Fechner M, et al. High temporal resolution parametric MRI monitoring of the initial ischemia/reperfusion phase in experimental acute kidney injury. PLoS One. 2013;8(2):e57411.

\section{Publish your work in this journal}

The International Journal of Nephrology and Renovascular Disease is an international, peer-reviewed open-access journal focusing on the pathophysiology of the kidney and vascular supply. Epidemiology, screening, diagnosis, and treatment interventions are covered as well as basic science, biochemical and immunological studies. The journal welcomes

\section{Dovepress}

original research, clinical studies, reviews \& evaluations, expert opinion and commentary, case reports and extended reports. The manuscript management system is completely online and includes a very quick and fair peerreview system, which is all easy to use. Visit http://www.dovepress.com/ testimonials.php to read real quotes from published authors. 